\title{
ENZYMATIC HYDROLYSIS LIGNIN DERIVED FROM CORN STOVER AS AN INTRINSTIC BINDER FOR BIO-COMPOSITES MANUFACTURE: EFFECT OF FIBER MOISTURE CONTENT AND PRESSING TEMPERATURE ON BOARDS' PROPERTIES
}

\author{
Xiaoyan Zhou, ${ }^{\mathrm{a}, \mathrm{b}, *}$ Lijuan Tan, ${ }^{\mathrm{a}}$ Weidong Zhang, ${ }^{\mathrm{a}}$ Chenglong Lv, ${ }^{\mathrm{a}}$ Fei Zheng, \\ Rong Zhang, ${ }^{\mathrm{a}}$ Guanben Du, ${ }^{\mathrm{c}}$ Bijun Tang, ${ }^{\mathrm{a}}$ and Xueyuan Liu ${ }^{\mathrm{a}}$
}

\begin{abstract}
Binderless fiberboards from enzymatic hydrolysis lignin (EHL) and cotton stalk fibers were prepared under various manufacturing conditions, and their physico-mechanical properties were evaluated. Full factorial experimental design was used to assess the effect of fiber moisture content and pressing temperature on boards' properties. In addition, differential scanning calorimetry (DSC) was used to obtain the glass transition temperature $\left(T_{g}\right)$ of EHL. We found that both fiber moisture content and pressing temperature had significant effects on binderless fiberboards' properties. High fiber moisture content and pressing temperature are suggested to contribute to the self-bonding improvement among fibers with lignin-rich surface mainly by thermal softening enzymatic hydrolysis lignin. In this experiment, the optimized pressing temperature applied in binderless fiberboard production should be as high as $190^{\circ} \mathrm{C}$ in accordance with the EHL $T_{g}$ value of $189.4^{\circ} \mathrm{C}$, and the fiber moisture content should be limited to less than $20 \%$ with a higher board density of $950 \mathrm{~kg} / \mathrm{m}^{3}$ to avoid the delamination of boards during hot pressing.
\end{abstract}

Keywords: Enzymatic hydrolysis lignin; Agricultural residues; Self-bonding; Fiberboard

Contact information: a: College of Wood Science and Technology, Nanjing Forestry University, Nanjing 210037, China; b: School of Chemistry and Chemical Engineering, Nanjing University, Nanjing 210093, China; c: Southwest Forestry University, Kuming, 650224, China;

*Corresponding author: xyzhou@yahoo.cn

\section{INTRODUCTION}

An increasing concern for air pollution and health risks has given impetus to research to reduce formaldehyde emissions from wood composites made from formaldehyde-based resins. The possibility of using replacement materials for formaldehydebased resins (such as isocyanate, soy protein-based adhesive, etc.) and excluding synthetic resins from wood composites are considered as the most effective solutions to this problem. In this regard many researchers have investigated the production of binderless boards from various origins since the 1980s (Jain and Handa 1982; Suzuki et al. 1998; Widyorini et al. 2005; Hashim et al. 2010). The results of these studies have shown that lignin from lignocellulosic materials plays an important role in the expression of binderless board performance (Okuda et al. 2006a, b).

Lignin, a phenolic polymer, is the second most abundant component of renewable biomass in nature and constitutes about 15 to $30 \%$ of the dry mass of wood and vascular 
plants. It acts as a binder in the cell walls of plants, consolidating the polysaccharide matrix and holding the hemicellulose and cellulose microfibres (Kumar et al. 2009). This offers potential for higher value-added applications of lignin generated from the papermaking and emerging cellulosic ethanol industries in renewable polymeric materials development. Several kinds of lignin, such as kraft lignin and lignosulfonate, have been added directly for binderless board manufacture and show that mechanical properties of binderless boards can be greatly improved (Anglès et al. 2001; Velásquez et al. 2003; Dam et al. 2004).

Enzymatic hydrolysis lignin (EHL) is a by-product of bio-ethanol production from lignocellulosic materials. Both the cellulosic and hemicellulosic fractions of biomass can be converted to simple sugars that can subsequently be fermented to ethanol. Therefore, current research and development attention has been focused on producing bio-ethanol from wood and agricultural residues. However, lignin, one of the major three components of lignocellulosics, plays a role as a barrier to enzymatic saccharification of cellulose and is considered as a waste product generated from the cellulosic ethanol processes. According to the survey, nearly 1 ton of residues is generated during the production of 1 ton bio-ethanol from lignocellulosic materials, of which 40 to $50 \%$ consists of enzymatic hydrolysis lignin (EHL). It is anticipated that the future lignocellulosic ethanol industry will generate large quantities of EHL (Zhu and Pan 2009). Value-added utilization of EHL not only can help offset the cost of bio-ethanol production and boost the economic viability of the bioethanol industry but also provide a source of renewable materials. EHL will likely be more active than that produced from conventional pulp mills due to enzymatic hydrolysis, which offers potential for higher value-added applications in renewable polymeric materials development. However, there is little information available on its value-added applications so far.

To explore the potential value-added applications of enzymatic hydrolysis lignin (EHL), binderless fiberboards from cotton stalk fibers with adding EHL as the intrinsic binder have been developed. In a previous study, the better properties of boards were achieved with an EHL addition amount of $10 \%$ based on the weight of oven-dried fibers. As part of a comprehensive research project, the effect of fiber moisture content and pressing temperature on binderless fiberboards' properties was investigated in this study, so that manufacturing conditions of binderless fiberboard from enzymatic hydrolysis lignin and cotton stalk fiber can be optimized.

\section{EXPERIMENTAL}

\section{Raw Materials and Preparation}

EHL was extracted from corn stover residues, which were derived from the production of bio-ethanol in the pilot plant in Hei Longjiang Province, with sodium hydroxide solution (Liu and Cheng 2007). Then EHL was ground and screened to an average diameter of $20 \mu \mathrm{m}$ and kept at a stable moisture content of $8 \%$.

Cotton (Gossypium hirsutum) stalk was harvested in an agricultural field of northern Jiangsu Province in China. From the sample stalk collected, its husks and other impurities were cleaned and its branches were removed. Then its stem was chipped and 
screened to an average size of $25 \times 10 \times 5 \mathrm{~mm}$ for fiber preparation. Chips were soaked in tap water overnight and then softened in a pressure tank with a steam pressure of 1.2 bar. The steamed chips were then fiberized rapidly using a laboratory atmospheric refiner. Refining was necessary with regard to the morphology and size of fibers. The fiber size distribution was determined by a PTI Fiber Classifer as illustrated in Fig. 1. The fibers were gradually collected and oven dried at $100{ }^{\circ} \mathrm{C}$ to a moisture content of $9.9 \%, 14.3 \%$, and $18.2 \%$, respectively for producing fiberboards.

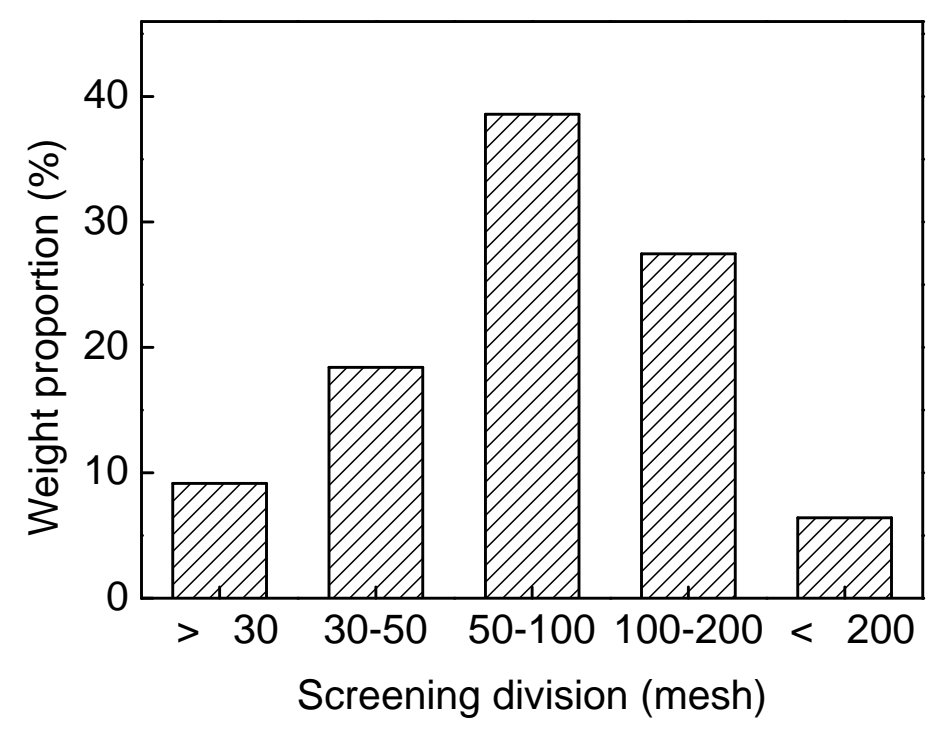

Fig. 1. Screening distribution of the cotton stalk fiber

\section{DSC Measurement}

A differential scanning calorimeter (DSC; 200F3, Netzsch, Germany) with high purity nitrogen as carrier gas was used to evaluate the thermal behaviors of the EHL with the heating rate of $10 \mathrm{~K} / \mathrm{min}$. Five samples were tested. For each scan, about $6 \mathrm{mg}$ of EHL was added to an aluminum capsule. The capsule was sealed and then heated from room temperature to $220{ }^{\circ} \mathrm{C}$. Calculated data involved automatic output through the system of Proteus Analyzer. The DSC curves were used to determine glass transition temperature $\left(T_{g}\right)$ of the sample using the step analysis method.

\section{Binderless Fiberboards Manufacture}

The prepared cotton stalk fibers were mixed with EHL in the proportion of $10 \%$ based on the weight of oven-dried fibers, since better properties of boards had been achieved with this addition amount in our previous study. Then the mixture was shaped using a forming box (300 $\mathrm{mm}$ in length and $300 \mathrm{~mm}$ in width). $4 \mathrm{~mm}$ thick cotton stalk fiberboard mats were prepared with a target density of $950 \mathrm{~kg} / \mathrm{m}^{3}$. After forming, the mats were loaded into a hot-press, and the two platens were closed to the target mat thickness that was controlled by thickness gauge. The pressing temperature was set at 170,190 , and $210^{\circ} \mathrm{C}$, respectively. Full factor experimental design was used to determine 
the effect of fiber moisture content and pressing temperature on boards' properties, as shown in Table 1. The pressing time and the initial pressing pressure were kept constant at $60 \mathrm{~s} / \mathrm{mm}$ and $5.0 \mathrm{MPa}$ respectively. For each condition three replicates were used, resulting in a total of 27 fiberboards.

Table 1. Full Factorial Experimental Design With Two Factors and Three Levers for Board Manufacture

\begin{tabular}{|c|c|c|}
\hline Run & Moisture content of fibers $(w t \%)$ & Pressing temperature $\left({ }^{\circ} \mathrm{C}\right)$ \\
\hline 1 & 9.9 & 170 \\
\hline 2 & 9.9 & 190 \\
\hline 3 & 9.9 & 210 \\
\hline 4 & 14.3 & 170 \\
\hline 5 & 14.3 & 190 \\
\hline 6 & 14.3 & 210 \\
\hline 7 & 18.2 & 170 \\
\hline 8 & 18.2 & 190 \\
\hline 9 & 18.2 & 210 \\
\hline
\end{tabular}

\section{Physical and Mechanical Properties of Fiberboards}

Prior to the evaluation of the mechanical and physical properties, the boards were conditioned at $25^{\circ} \mathrm{C}$ and $65 \pm 5 \%$ relative humidity $(\mathrm{RH})$ until the boards reached equilibrium moisture content for properties examination. The boards were characterized according to the Chinese National Standard for Medium Density Fiberboard (MDF) (GB/T 11718-2009) for internal bonding strength (IBS), modulus of rupture (MOR) and thickness swelling (TS).

Two static bending specimens $(200 \mathrm{~mm} \times 50 \mathrm{~mm})$ were prepared from each board for MOR testing. The three-point static bending test was conducted over an effective span of $150 \mathrm{~mm}$, at a loading speed of $10 \mathrm{~mm} / \mathrm{min}$. Six internal bonding strength (IBS) specimens $(50 \mathrm{~mm} \times 50 \mathrm{~mm})$ and four thickness swelling (TS) $\left(24 \mathrm{~h}\right.$ immersion in $20^{\circ} \mathrm{C}$ water) specimens $(50 \mathrm{~mm} \times 50 \mathrm{~mm})$ were cut from each board for testing. The density of each specimen for MOR, IBS, and TS were also measured before testing for the purpose of statistical analysis.

The actual densities of the specimens vary around the target density due to the horizontal density variation of boards, resulting from mat forming. As is well known, density has a significant effect on board performance. Hence, the board properties must be adjusted to the same density level before comparison. All of the experimental values obtained were corrected to the target board density of $0.95 \mathrm{~g} / \mathrm{cm}^{3}$ based on the linear regression between board density and properties (Xing et al. 2006).

\section{RESULTS AND DISCUSSION}

\section{Effect of Fiber Moisture Content and Pressing Temperature on IBS}

The internal bonding strength (IBS) refers to the strength of the bonding between fibers, which is an important consideration to ensure that the board will not delaminate during post-processing. The fiber moisture content and the pressing temperature play important roles in the development of inter-fiber bonds during hot-pressing. The results 
of ANOVA revealed that both fiber moisture content and pressing temperature were very significant factors for IBS, as shown in Table 2. As depicted in Fig. 2, the IBS increased significantly with increasing pressing temperature and fiber moisture content. At the low pressing temperature of $170{ }^{\circ} \mathrm{C}$, the lowest IBS value of boards was observed with the low fiber moisture content of $9.9 \%$, while the IBS was improved to about twice of the lowest one when the pressing temperature and the fiber moisture content were raised to $210^{\circ} \mathrm{C}$ and $18.2 \%$, respectively.

Table 2. ANOVA Table of Fiber Moisture Content (MC) and Pressing Temperature $(\mathrm{T})$ in Relation to IBS

\begin{tabular}{|c|c|c|c|c|c|}
\hline Factor & SS* $^{*}$ & $\mathrm{df}^{*}$ & $\mathrm{MS}^{*}$ & $F^{*}$ & $P^{*}$ \\
\hline $\mathrm{MC}$ & 0.0815 & 2 & 0.0408 & 14.156 & 0.0002 \\
\hline$T$ & 0.0302 & 2 & 0.0151 & 5.241 & 0.0161 \\
\hline $\mathrm{T} \times \mathrm{MC}$ & 0.0276 & 4 & 0.0069 & 2.398 & 0.0883 \\
\hline Error & 0.0518 & 18 & 0.0029 & & \\
\hline Total SS & 0.1912 & 26 & & & \\
\hline
\end{tabular}

The internal bonding between lignocellulosic fibers without synthetic adhesives is mainly due to: hydrogen-binding between fibers, condensation reaction in lignin (Okuda et al. 2006a, 2006b), and lignin-polysaccharides cross-linking reactions, such as ligninfurfural linkages (Suzuki et al. 1998). Moreover, the formation of covalent bonds between the lignocellulose polymers results in intermolecular forces that are much stronger than those created by hydrogen bonds (Back 1991). Recent investigations have demonstrated that fibers with lignin-rich surfaces could improve the mechanical properties of binderless boards by mechanical entanglement of the softened lignin molecules under pressure and temperature, possibly accompanied by the formation of covalent bonds (Okuda et al. 2006a, 2006b; Quintana et al. 2009). Our previous results proved that better properties of binderless fiberboards from cotton stalk could be obtained with the addition of EHL at a 10\% level. As a plastic material, lignin would be fused together under pressure and temperature. Therefore, high pressing temperatures increase the lignin fluidity on fibers, improving lignin distribution and forming better inter-fiber bonds. In addition, it is obvious that increasing fiber moisture content will promote hydrogen bonds between fibers, and it is of great benefit to thermal softening of the lignin, which is expected to be particularly important for binderless fiberboard manufacture and has been suggested to contribute to the self-bonding improvement (Okuda et al. 2006a; Baldwin and Goring 1968).

\section{Effect of Fiber Moisture Content and Pressing Temperature on MOR}

The effect of fiber moisture content and pressing temperature on the modulus of rupture (MOR) of binderless fiberboards is shown in Table 3 and Fig. 3. The smaller probability values in Table 3 show that fiber moisture content and pressing temperature were very significant factors for MOR. Under a lower fiber moisture content of $9.9 \%$, the boards did not exhibit satisfactory bending strength. Meanwhile, the MOR was not improved dramatically with increasing pressing temperature. However, the MOR was 
improved remarkably with raising of the fiber moisture content. The highest MOR value was $20.75 \mathrm{MPa}$, which was achieved with the fiber moisture content of $18.2 \%$ and a pressing temperature of $210^{\circ} \mathrm{C}$, resulting in behavior similar to IBS.

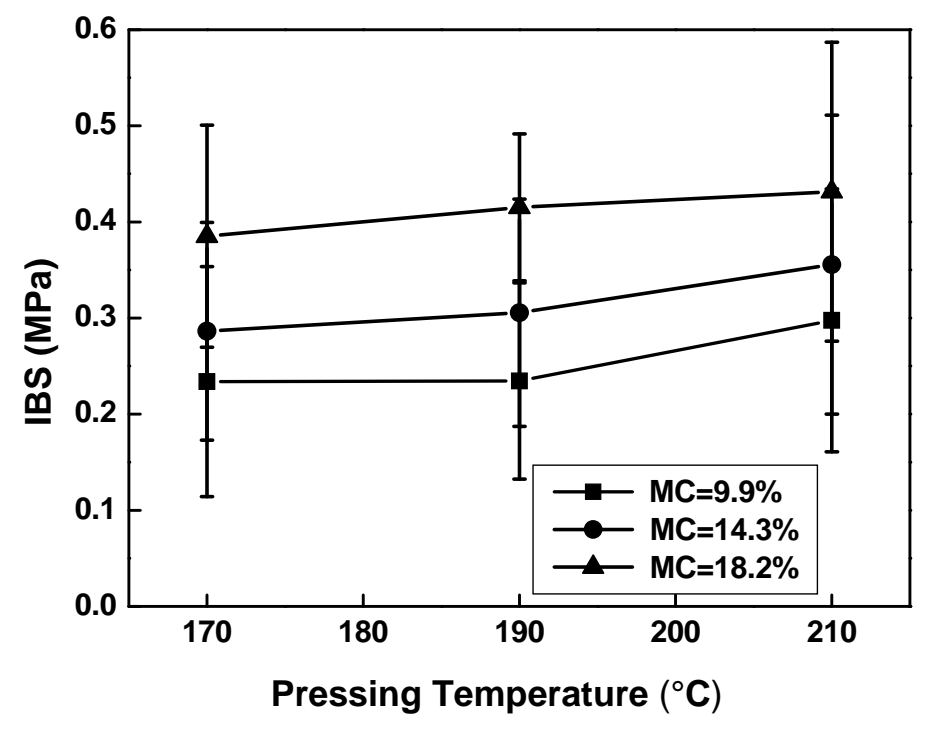

Fig. 2. Effect of fiber moisture content and pressing temperature on IBS

Table 3. ANOVA Table of Fiber Moisture Content (MC) and Pressing Temperature $(\mathrm{T})$ in Relation to MOR

\begin{tabular}{|c|c|c|c|c|c|}
\hline Factor & $\mathrm{SS}^{*}$ & $\mathrm{df}^{*}$ & $\mathrm{MS}^{*}$ & $F^{*}$ & $\mathrm{P}^{*}$ \\
\hline $\mathrm{MC}$ & 155.54 & 2 & 77.77 & 33.85 & 7.96E-07 \\
\hline $\mathrm{T}$ & 73.23 & 2 & 36.61 & 15.94 & 0.0001 \\
\hline $\mathrm{T} \times \mathrm{MC}$ & 16.05 & 4 & 4.01 & 1.75 & 0.1837 \\
\hline Error & 41.35 & 18 & 2.30 & & \\
\hline Total SS & 286.17 & 26 & & & \\
\hline
\end{tabular}

Since the value of MOR depends on the bonding strength among fibers and the individual fiber strength, better inter-fiber bonds is suggested to contribute to the bending strength improvement with the same quality of fibers. As shown by the above results, higher IBS was obtained with increasing fiber moisture content, resulting in a marked fall of the softening temperatures of lignin. Enhancing the bonding strength among fibers with EHL deposited on the surface has a beneficial effect on MOR of binderless fiberboards. In addition, higher fiber moisture content and pressing temperature result in plasticizing the fibers so that densification occurs more easily, giving rise to higher density of boards, particularly involving the surface layer which determines the MOR value. However, in the preliminary experiment, the board was found to delaminate when raising the fiber moisture content up to $20 \%$. Therefore, the fiber moisture content had to be limited to less than $20 \%$ with a higher board density of $950 \mathrm{~kg} / \mathrm{m}^{3}$. 


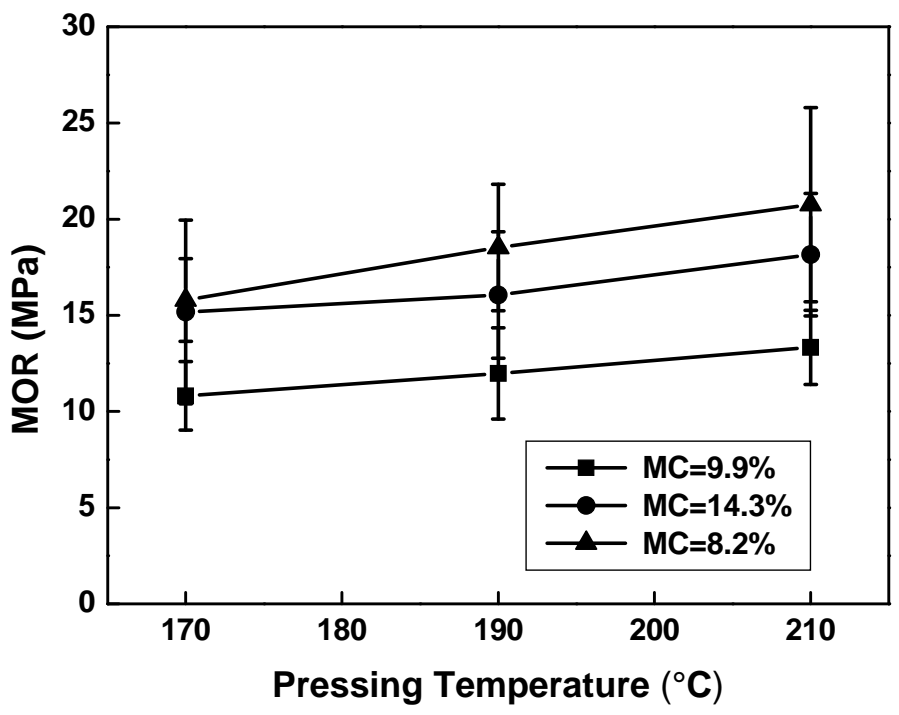

Fig. 3. Effect of fiber moisture content and pressing temperature on MOR

\section{Effect of Fiber Moisture Content and Pressing Temperature on TS}

Figure 4 shows the thickness swelling (TS) values of binderless fiberboard after $24 \mathrm{~h}$ of immersion in water at $20^{\circ} \mathrm{C}$. Binderless fiberboard made from cotton stalk fibers with a moisture content of $9.9 \%$ under lower pressing temperature presented a considerably higher TS of $86.98 \%$, and fibers were found to be extracted from some samples, which illustrated that the fiber-fiber bonding is relatively weak under such manufacturing conditions. However, with increasing fiber moisture content and pressing temperature, the TS values were decreased significantly. The fiberboard from $18.2 \% \mathrm{MC}$ fibers pressed under the temperature of $210^{\circ} \mathrm{C}$ recorded the lowest TS value of $32.35 \%$, which was about one third of the highest one. The results of ANOVA, as shown in Table 4, also indicate that fiber moisture content and pressing temperature had very significant effects on TS.

Table 4. ANOVA Table of Fiber Moisture Content (MC) and Pressing Temperature $(\mathrm{T})$ in Relation to TS

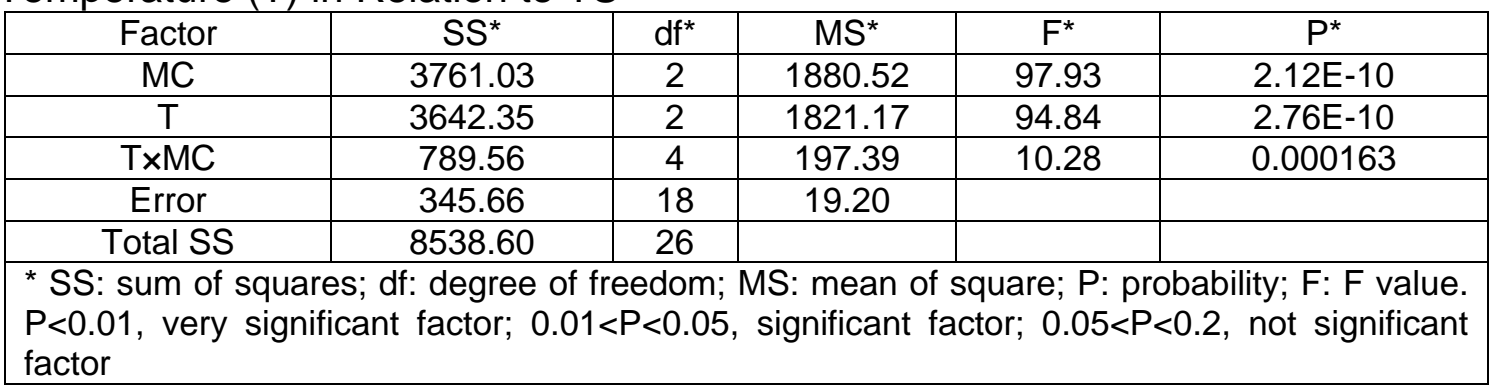




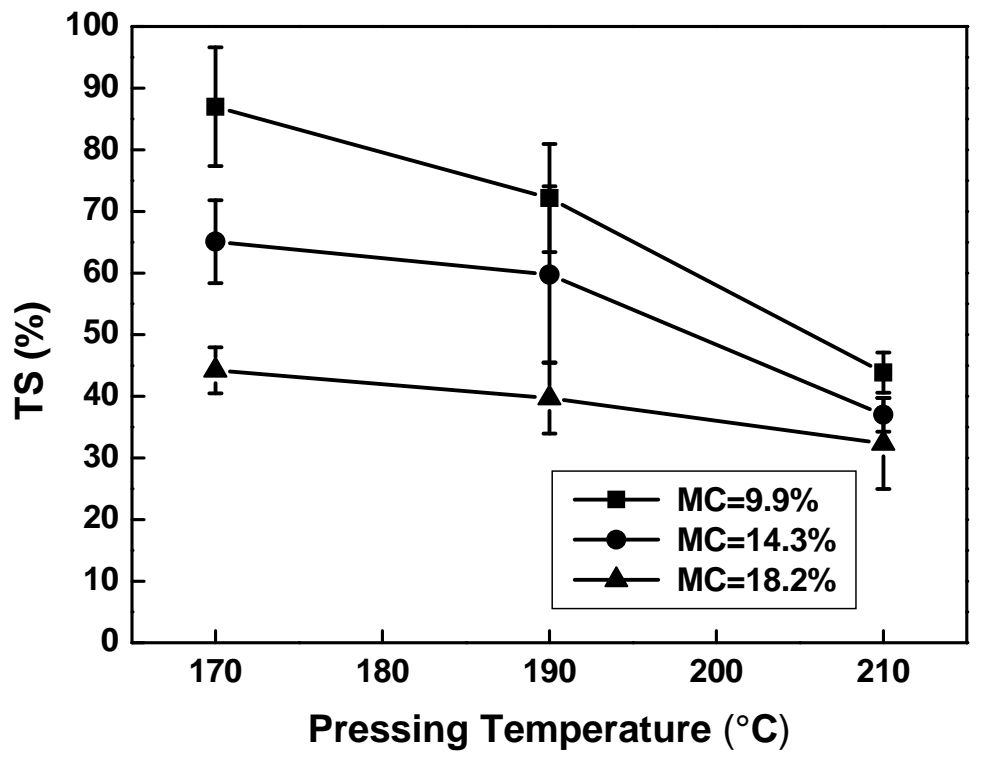

Fig. 4. Effect of fiber moisture content and pressing temperature on TS

The main causes of thickness swelling of fiberboards are recovery of compressed fibers and breakage of bonded area among fibers. Results from previous studies have shown that adding EHL can be advantageous to improve the TS of binderless fiberboard. It indicates that the reduction in hygroscopicity, due to deposition of hydrophobic EHL on the fiber surface, is one factor for the improved dimensional stability resulting from hindering the shrinkage of compressed fiber after being soaked in water. The high dimensional stability also contributed to the improvement of self-bonding among fibers under high fiber moisture content and pressing temperature.

Comparing the above results to the Chinese MDF standard (GB/T 11718-2009, IBS $\geqslant 0.55 \mathrm{MPa}, \mathrm{MOR} \geqslant 23 \mathrm{MPa}$, TS $\leqslant 35 \%$ ), which was designed for fiberboards with synthetic adhesives, we would find that IBS obtained from the cotton stalk panel products with EHL as an intrinstic binder is very low while TS is very high. It is suggested that one possible way to improve the adhesion is to chemically activate the lignin, so that binding between the fibers can be promoted during hot pressing. RF-oxygen-plasma treatment of lignin was proposed, and its effects on properties of fiberboards has been investigated. A subsequent paper should shed some light on this.

\section{DSC Analysis}

DSC defines the glass transition temperature $\left(T_{g}\right)$ as a change in the heat capacity as the polymer matrix goes from a glassy state to a rubbery state. This point is determined by a change in slope in DSC curves. Determining the $T_{g}$ value of EHL can help in the optimization of the pressing temperature when producing binderless fiberboards. As shown in Fig. 4, the observed $T_{g}$ value for extracted enzymatic hydrolysis lignin from the production residues of bio-ethanol occurred at a temperature of $189.4^{\circ} \mathrm{C}$. In general, the 
$T_{g}$ of lignin ranges from 127 to $193^{\circ} \mathrm{C}$, depending on their source and method of isolation (Goring 1971). These ranges agree well with our data.

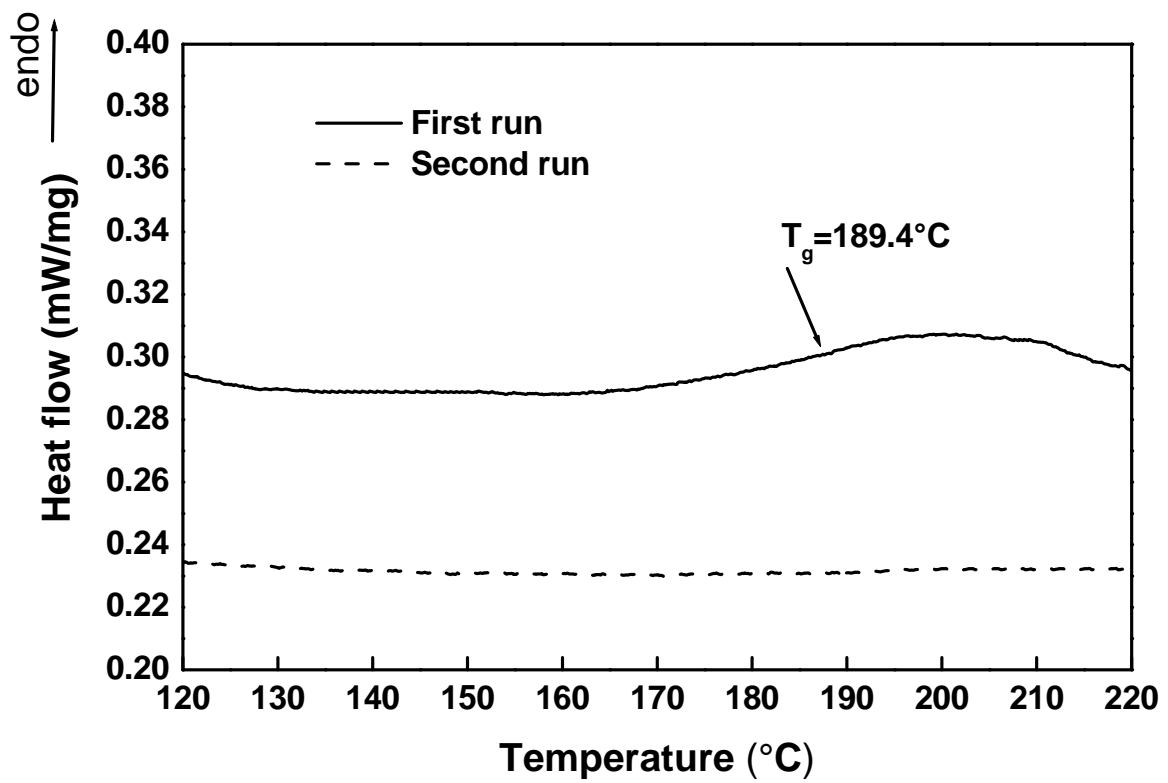

Fig. 4. DSC curves of enzymatic hydrolysis lignin (EHL). First and second heating ramp

The $T_{g}$ of lignin is high compared to the $T_{g}$ 's of most synthetic polymers. The high $T_{g}$ is probably due to hydrogen bonding caused by the presence of phenolic hydroxyl groups in the main chain. The chemical structure of lignin, particularly the aromatic ring present in the main chain, is also thought to contribute to the high $T_{g}$ (Feldman et al. 2001). Enzymatic hydrolysis lignin generated through the process of steam explosion and enzymatic hydrolysis exhibits a relatively high $T_{g}$, resulting in most of the original lignin structure not being affected during this process (Kumar et al. 2009).

Bouajila has reported that the difference $T-T_{g}$ ( $T$, local temperature of board during hot pressing; $T_{g}$, local glass transition temperature) is correlated to mechanical properties of binderless fiberboards (Bouajila et al. 2005). It is obvious that poor properties of binderless fiberboards from enzymatic hydrolysis lignin and cotton stalk fiber were obtained when the pressing temperature was less than the $T_{g}$ value of EHL. Thermal softening of lignin is suggested to play an important role in the expression of binderless fiberboard performance. The pressing temperature applied in binderless fiberboard production should therefore remain as high as $190^{\circ} \mathrm{C}$ in this experiment.

We also can find from Fig. 4 that the endotherm at $189.4^{\circ} \mathrm{C}$ in the first heating ramp disappeared in the second run. As a possible explanation for this, it can be presumed that the disappearance of this peak may be due to partly irreversible repolymerization reactions in lignin during hot pressing (Dam et al. 2004; Varma et al. 1986), which is essential for the development of a processing technique for binderless boards. 


\section{CONCLUSIONS}

To explore the potential of enzymatic hydrolysis lignin (EHL) as an alternative to synthetic adhesives for manufacturing binderless fiberboards from agricultural residues, the effect of fiber moisture content and pressing temperature on physico-mechanical properties of binderless fiberboards from enzymatic hydrolysis lignin and cotton stalk fiber was investigated, and manufacturing conditions were optimized in this paper. The main conclusions can be summarized as follows:

(1) Both fiber moisture content and pressing temperature have significant effect on binderless fiberboards' properties. The physico-mechanical properties of boards were increased dramatically with the raising of fiber moisture content (on entering the press) and pressing temperature. It is suggested that high fiber moisture content and pressing temperature accelerate self-bonding among fibers with lignin-rich surfaces, mainly by thermal softening enzymatic hydrolysis lignin.

(2) According to the $T_{g}$ value of EHL obtained from DSC curves, the optimized pressing temperature applied in binderless fiberboard production should remain as high as $190^{\circ} \mathrm{C}$, and fiber moisture content should be limited to less than $20 \%$ with a higher board density of $950 \mathrm{~kg} / \mathrm{m}^{3}$ to avoid delamination of boards during hot pressing.

\section{ACKNOWLEDGMENTS}

The authors are indebted to financial support by projects from the National Natural Science Foundation of China (Grant No. 31070504), the State Key Program of National Natural Science of China (Grant No. 30930074), the Key Natural Science Foundation of the Jiangsu Higher Education Institutions (Grant No. 08KJA220001), the Governmental Public Industry Research Special Funds (Grant No. 201004001), and the "Science Support" Program of Jiangsu Province (Grant No. BE2009404). Sincere thanks go to the research group of bio-ethanol from lignocellulosic materials from Nanjing Forestry University for providing enzymatic hydrolysis lignin and Jiangsu Engineering Research Center of Fast-growing Trees and Agri-fiber Materials for providing equipment for this study. The authors also thank Dr. Dongshan Zhou and Dr. Wei Jiang from Nanjing University for valuable discussions.

\section{REFERENCES CITED}

Anglès, M. N., Ferrando, F., Farriol, X., and Salvadó, J. (2001). "Suitability of steam exploded residual softwood for the production of binderless panels. Effect of the pretreatment severity and lignin addition," Biomass Bioenergy. 21, 211-224.

Back, E. L. (1991). "Oxidative activation of wood surfaces for glue bonding," Forest Prod. J. 41, 30-36.

Baldwin, S. H., and Goring, D. A. I. (1968). "The thermoplastic and adhesive behaviour of thermomechanical pulp from steamed wood," Sven. Papperstidn. 71, 646-650. 
Bouajila, J., Limare, A., Joly, C., and Dole, P. (2005). "Lignin plasticization to improve binderless fiberboard mechanical properties," Polym. Eng. Sci. 45, 809-816.

Dam, J. E. G., Oever, M. J. A., Wouter, T., Keijsers, E. R. P., and Peralta, A. G. (2004). "Process for production of high density/high performance binderless boards from whole coconut husk. Part 1: Lignin as intrinsic thermosetting binder resin," Ind. Crop. Prod. 19, 207-216.

Feldman, D., Campanelli, B. J., and Zhu, H. (2001). "Blends of vinylic copolymer with Plasticized lignin: Thermal and mechanical properties," J. Appl. Polym. Sci. 81, 861874.

Goring, D.A.I. (1971). "Polymer properties of lignin and lignin derivatives," in: K. V. Sarkanen, and C. H. Ludwig (eds.), Lignins, Wiley, New York.

Hashim, R., Nadhari, W., Sulaiman, Q., Kawamura, F., Hiziroglu, S., Sugimoto, T., Tseng, T. G., and Tanaka, R. (2010). "Characterization of raw materials and manufactured binderless particleboard from oil palm biomass," Materials and Design. doi:10.1016/j.matdes.2010.05.059.

Jain, S. K., and Handa, S. K. (1982). "A press for producing binderless board from agricultural wates," Research and Industry. 27, 121-123.

Kumar, M. N. S., Mohanty, A. K., Erickson, L., and Misra, M. (2009). "Lignin and its applications with polymers," J. Biobased Mater. Bio. 3, 1-24.

Liu, X. L., and Cheng, X. S. (2007). "Study on separation and structure of enzymatic hydrolysis lignin,” J. Cellul. Sci. Technol. 15, 41-46.

Okuda, N., Hori, K., and Sato, M. (2006a). "Chemical changes of kenaf core binderless boards during hot pressing (I): Influence of the pressing temperature condition," $J$. Wood Sci. 52, 244-248.

Okuda, N., Hori, K., and Sato, M. (2006b). "Chemical changes of kenaf core binderless boards during hot pressing (II): Effects on the binderless board properties," J. Wood Sci. 52, 249-254.

Quintana, G., Velasquez, J., Betancourt, S., and Ganan, P. (2009). "Binderless fiberboard from steam exploded banana bunch," Ind. Crop. Prod. 29, 60-66.

Suzuki, S., Shintani, H., Park, S. Y., Saito, K., Laemsak, N., Okuma, M., and Iiyama, K. (1998). "Preparation of binderless boards from steam exploded pulps of oil palm (Elaeis guneensis Jaxq.) fronds and structural characteristics of lignin and wall polysaccharides in steam exploded pulps to be discussed for self bonding," Holzforschung 52, 417-426.

Varma, D. S., Varma, M., and Varma, I. K. (1986). "Thermal behaviour of coir fibres," Thermochim Acta 108, 199-210.

Velásquez, J. A., Ferrando, F., and Salvadó, J. (2003). "Effects of kraft lignin addition in the production of binderless fiberboard from steam exploded Miscanthus sinensis," Ind. Crop. Prod. 18, 17-23.

Widyorini, R., Higashihara, T., Xu, J. Y., Watanabe, T., and Kawai, S. (2005). "Selfbonding characteristics of binderless kenaf core composites," Wood Sci. Tech. 39, 651-662.

Xing, C., Deng, J., Zhang, S. Y., Riedl, B., and Cloutier, A. (2006). "Properties of MDF from black sprue tops as affected by thermomechaical refining conditions," Holz Roh Werkst. 64, 507-512. 
Zhu, J. Y., and Pan, X. J. (2010). "Woody biomass pretreatment for cellulosic ethanol production: Technology and energy consumption evaluation," Bioresource Technol. $101,4992-5002$.

Article submitted: September 18, 2010; Peer review completed: November 30, 2010;

Revised version received and accepted: December 2, 2010; Published: December 4, 2010. 